\title{
Responses to increasing exercise upon reaching the anaerobic threshold, and their control by the central nervous system
}

\author{
Ana B Peinado ${ }^{1 *}$, Jesús J Rojo ${ }^{1}$, Francisco J Calderón ${ }^{1}$ and Nicola Maffulli ${ }^{2,3}$
}

\begin{abstract}
The anaerobic threshold (AT) has been one of the most studied of all physiological variables. Many authors have proposed the use of several markers to determine the moment at with the AT is reached. The present work discusses the physiological responses made to exercise - the measurement of which indicates the point at which the AT is reached - and how these responses might be controlled by the central nervous system. The detection of the AT having been reached is a sign for the central nervous system (CNS) to respond via an increase in efferent activity via the peripheral nervous system (PNS). An increase in CNS and PNS activities are related to changes in ventilation, cardiovascular function, and gland and muscle function. The directing action of the central command (CC) allows for the coordination of the autonomous and motor systems, suggesting that the AT can be identified in the many ways: changes in lactate, ventilation, plasma catecholamines, heart rate (HR), salivary amylase and muscular electrical activity. This change in response could be indicative that the organism would face failure if the exercise load continued to increase. To avoid this, the CC manages the efferent signals that show the organism that it is running out of homeostatic potential.
\end{abstract}

Keywords: Physiological response, Exercise, Central governor, Fatigue

\section{Introduction}

The AT has been one of the most studied of all physiological variables [1-4]. In human studies, the interest of researchers has ranged from its better comprehension $[5,6]$ to its use in medicine [7-9] and training [9-11].

The term 'anaerobic threshold' was coined by Wasserman and McIlroy [12] when using the respiratory exchange ratio (RER) to detect the beginning of anaerobic metabolism in patients with heart problems performing stress tests [12]. Later, Wasserman et al. [13] defined the AT as: 1) a non-linear increase in ventilation (Ve), 2) a non-linear increase in the elimination of $\mathrm{CO}_{2}\left(\mathrm{VCO}_{2}\right)$, 3) an increase in the end-tidal partial pressure of $\mathrm{O}_{2}$ during a series of breaths $\left(\mathrm{PetO}_{2}\right)$ with no corresponding drop in the end-tidal partial pressure of $\mathrm{CO}_{2}\left(\mathrm{PetCO}_{2}\right)$, and 4) an increase in the RER with work load (all during an incremental exercise test) [13].

\footnotetext{
* Correspondence: anabelen.peinado@upm.es

${ }^{1}$ Department of Health and Human Performance, Technical University of Madrid, Martín Fierro 7, 28040 Madrid, Spain

Full list of author information is available at the end of the article
}

Skinner and McLellan [14] constructed the triphasic model (Figure 1), which uses gaseous exchange (breathing) variables and which distinguishes two thresholds: ventilatory threshold $1\left(\mathrm{VT}_{1}\right)$ and ventilatory threshold 2 $\left(\mathrm{VT}_{2}\right)$. According to these authors, $\mathrm{VT}_{2}$ is related to AT, since both are reached at the same time. Unfortunately, in the literature, $\mathrm{VT}_{2}$ is known by different names (Table 1), which has led to much confusion. Moreover, the definition of this phenomenon is clearly controversial as many different methodologies have been proposed to determine the AT.

The $\mathrm{VT}_{2}$ is likely reached at the same time as the anaerobic lactate threshold (LT). The LT is the moment at which, during an incremental stress test, the plasma concentration of lactate increases above resting value. The intense and ongoing debate about this threshold is mainly based on terminology and/or the physiological background of LT concepts [20]. Thus, the AT, $\mathrm{VT}_{2}$ and $\mathrm{LT}$ are all supposed to be reached at the same time. 


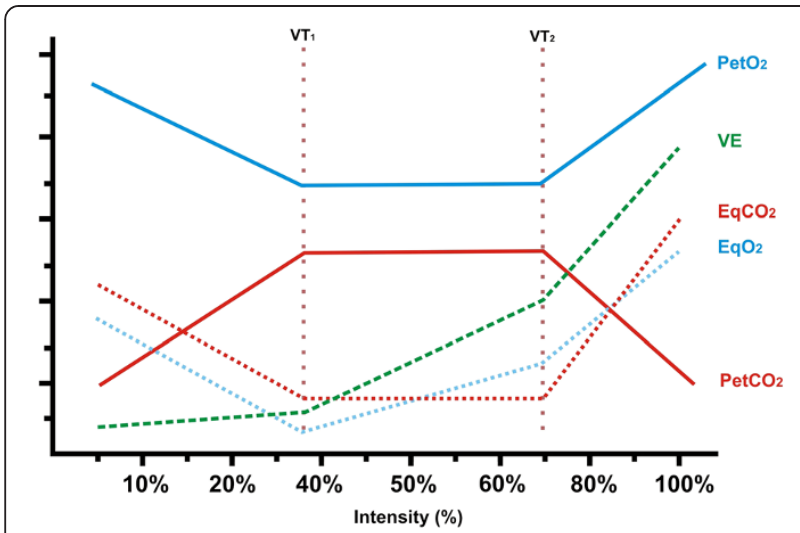

Figure 1 Triphasic model described by Skinner and McLellan [14].

However, debate still surrounds the exact relationship between $\mathrm{VT}_{2}$ and LT [21].

On the other hand, the mechanisms that regulate ventilation during exercise are not entirely understood [22]; the use of $\mathrm{VT}_{2}$ for the determination of AT, may, therefore, not be entirely reliable. Many authors therefore propose the use of other markers to determine the moment at with the AT is reached. For example, Davis et al. [23] proposed the determination of this point via the increase in plasma catecholamines $\left(\mathrm{AT}_{\text {catecholamines }}\right)$ during an incremental exercise test. Yet others have proposed determining the electromyographic threshold $\left(\mathrm{AT}_{\mathrm{EMG}}\right)$ [24]. Others still have proposed measuring the concentration of salivary amylase $\left(\mathrm{AT}_{\text {saliva }}\right)$ [25]; it is proposed that when the AT is reached, a change in the concentration of this enzyme becomes noticeable. Conconi et al. [26] proposed that a change in slope of the relationship between heart rate (HR) and exercise intensity $\left(\mathrm{AT}_{\text {Conconi }}\right)$ be used as a marker of $\mathrm{AT}$, although this remains controversial and several authors concluded that most haemodynamic variables, including $\mathrm{HR}$, are unsuitable for indirect assessment of the AT [27].

The present work discusses the physiological responses made to exercise - the measurement of which indicates the point at which the AT is reached - and how

Table 1 Different terms used to refer to ventilatory threshold 2 as recorded by Orr [15]

\begin{tabular}{ll}
\hline Name & Authors \\
\hline Aerobic-anaerobic threshold & Mader and Heck (1976) [16] \\
Anaerobic threshold & Kinderman et al. (1979) [17] \\
Individual anaerobic threshold & Stegmann et al. (1981) [18] \\
$\begin{array}{l}\text { Onset blood lactate accumulation } \\
\text { (OBLA) }\end{array}$ & Sjodin and Jacobs (1981) [19] \\
Anaerobic threshold & Skinner and McLellan (1980) [14] \\
\hline
\end{tabular}

these responses might be controlled by the central nervous system (CNS) (Figure 2). Many questions remain as to how the CNS coordinates responses to the AT having been reached. What type of information is processed by the CNS in order for it to respond? How is this information analysed?

\section{Detecting the different signals that the anaerobic} threshold has been reached, and mounting a response The detection of the AT having been reached is a sign for the CNS to respond via an increase in efferent activity via the peripheral nervous system (PNS). This response is regulated by the reticular formation, with the involvement of the brainstem nuclei and the limbic system. The limbic system maintains bi-directional communication (afferent and efferent) with the CNS, and participates in autonomic regulation via the voluntary and autonomous nervous systems. This probably alerts the entire organism that the AT has been reached and that a response is required. Figure 2 shows how an increase in CNS and PNS activities are related to changes in ventilation, cardiovascular function, and gland and muscle function.

\section{Changes in different systems upon reaching the AT}

During exercise the composition of the saliva may change via an increase in sympathetic activity. Indeed the $\mathrm{AT}$ can be pinpointed via the $\mathrm{AT}_{\text {saliva. In humans, }}$ there are two types of salivary gland: the major glands (including the parotid, submaxillary and sublingual glands), and the minor glands (lingual glands). The major glands are controlled by the salivatory nuclei (superior and inferior) which are close to the dorsal nucleus of the vagus nerve, above the pontobulbar union [28]. These glands are innervated by sympathetic and parasympathetic neurons. The parotid glands receive sympathetic fibres from the external carotid plexus, along with parasympathetic fibres via the tympanic branch of the glossopharyngeal nerve, following synapses in the otic ganglion [28]. The afferent fibres of the salivary nuclei have not been well identified. Figure 3 shows the changes that occur in salivary amylase when the AT is reached [25].

During exercise the plasma concentration of adrenaline and noradrenaline may change. These hormones are secreted by the non-myelinated postsynaptic terminals of the sympathetic nervous system, and the medulla of the adrenal gland. The latter is innervated by the myelinated preganglionic fibres of the suprarenal plexus (formed by branches of the coeliac ganglion and the major splanchnic nerve) [28]. For their size, the autonomic innervation of the chromaffin cells is greater than that of any other type of cell. The nervous activity of 


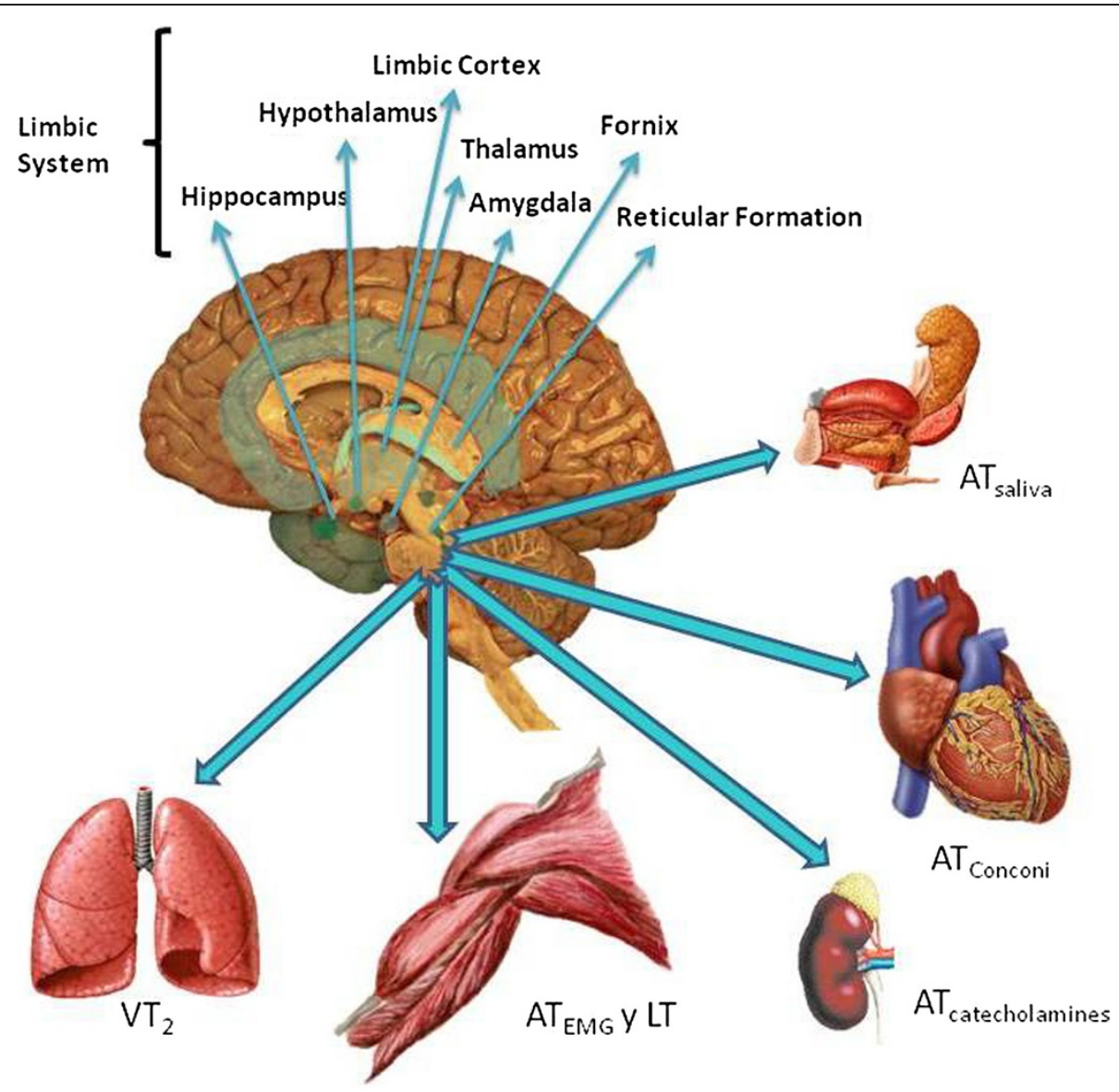

Figure 2 Proposed relationship between the nervous system and the different means of determining that the AT has been reached. $A T_{\text {saliva: }}$ saliva threshold; $\mathrm{AT}_{\text {catecholamines: }}$ catecholamines threshold; $\mathrm{AT}_{\mathrm{EMG}}$ : electromyographic threshold; $\mathrm{AT}_{\text {Conconi: }}$ heart rate threshold proposed by Conconi; $\mathrm{VT}_{2}$ : ventilatory threshold 2; LT: lactate threshold.

thoracic segments 5-12, the intermediate neurones of which connect to the chain of corresponding sympathetic ganglia, terminate in the coeliac ganglion via the major and minor splanchnic nerves, and are responsible for the activation of the adrenal gland. Figure 4 shows how the increase in sympathetic nervous activity leads to an increase in catecholamine release. The reticular formation in the brainstem and spinal cord (which are controlled by the prosencephalic level of the limbic system) regulates the response.

Finally, muscular electrical activity changes during exercise (Figure 5), along with the lactate concentration, as anaerobic metabolism becomes more prevalent. The increase in lactate production mirrors an increased activity in type II or fast twitch (FT) muscle fibres. According to Burke [29], the activation of these fibres is preferential once the AT has been reached. The increase in their activity explains the increase in muscular electrical activity, and supports the idea that the AT can be identified via the $\mathrm{AT}_{\mathrm{EMG}}$.

\section{Possible control mechanisms}

It is not clear which nervous centres are involved in producing and coordinating the responses to AT when this has been reached. However, these responses involve many organs, tissues and glands, and therefore many CNS structures are probably involved. The anatomo-functional relationships between the different structures of the encephalon preclude the recognition of any particular area of the brain as the centre governing the efferent signals involved in any response. However, in this response system, the brainstem and spinal cord are likely subordinate to the primitive structures of the pros encephalon. However, this paper uses the term central governor or central command (CC) to designate this functional entity [30].

The nervous centres and relationships between them that are involved in the processing of stress stimuli within the CNS are not well known. However, several hypotheses exist with respect to the role of the $\mathrm{CC}$ in fatigue [31], and different parts of the CNS (cortex, 


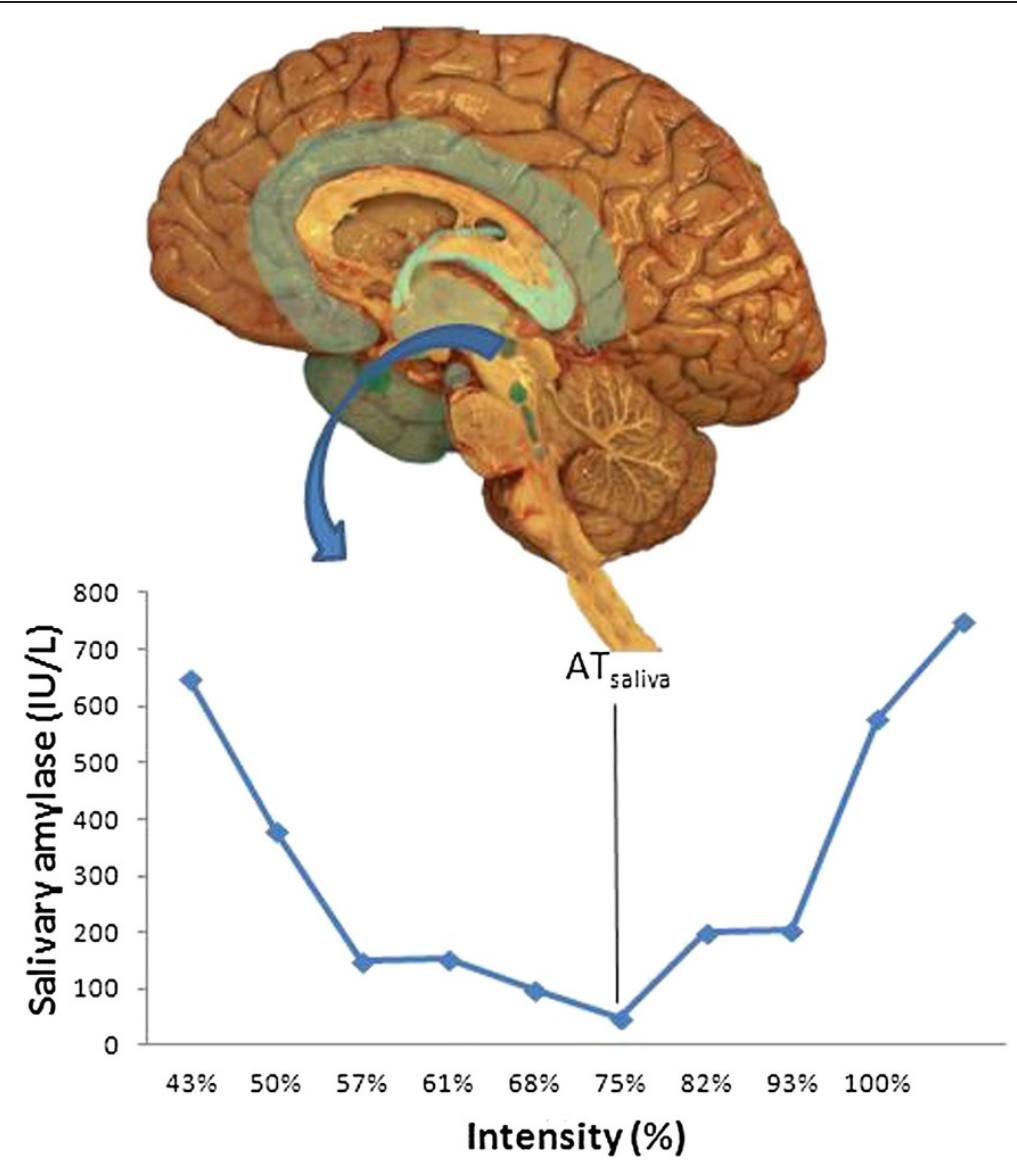

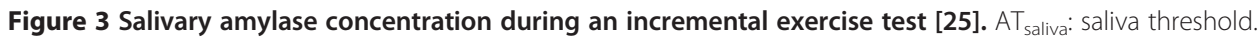

hippocampus, brainstem, encephalon, hypothalamus and amygdala) have been related directly or indirectly with the physiological response to stress [32]. The amygdala, which forms part of the limbic system, appears to have an important role in the latter. Further, its relationship with the hypothalamus and the brainstem suggest that this structure takes part in the activation and control of autonomic efferent activity. The nervous links between the limbic system and the hypothalamus, and then the brainstem nuclei, would appear to be responsible for sending efferent signals to responding tissues and organs. Since the peripheral sensory signals from mechanoreceptors, chemoreceptors and baroreceptors arrive instantly at the cardiac and respiratory control centres, the $\mathrm{CC}$ must deliver autonomic efferent responses that coincide in time.

Anatomically and electrophysiologically, the descending pathways that act directly or indirectly on the motor neurons of the anterior horn of the spinal cord include: 1) the corticospinal pathway, 2) the vestibulospinal (medial and lateral) pathways, 3 ) the reticulospinal (lateral and medial) pathways, 4) the rubrospinal pathway, 5) the interstitiospinal pathways, and 6) the tectoespinal pathway.

An increase in the activity of the descending motor pathways as a whole explains the increase in the activity of the FT fibres, and thus an increase in the lactate concentration. The efferent systems of the supraspinal centres communicate with motor neurones of different thresholds; they can therefore excite those with the highest thresholds (FT fibres) and inhibit those with the lowest (slow twitch [ST] fibres) [29]. It has also been suggested that populations of motor neurons may be activated differently, following different orders of recruitment [33]. This would allow the activation of an entire motor neurone population and avoid their saturation at a low level of activation, responding to spinal and supraspinal influences.

The electrophysiological characteristics of motor neurones, and the effect of the descending pathways on the pool of spinal motor neurons, explains the increase the activity of those innervating the FT once the AT has been reached [29]. 

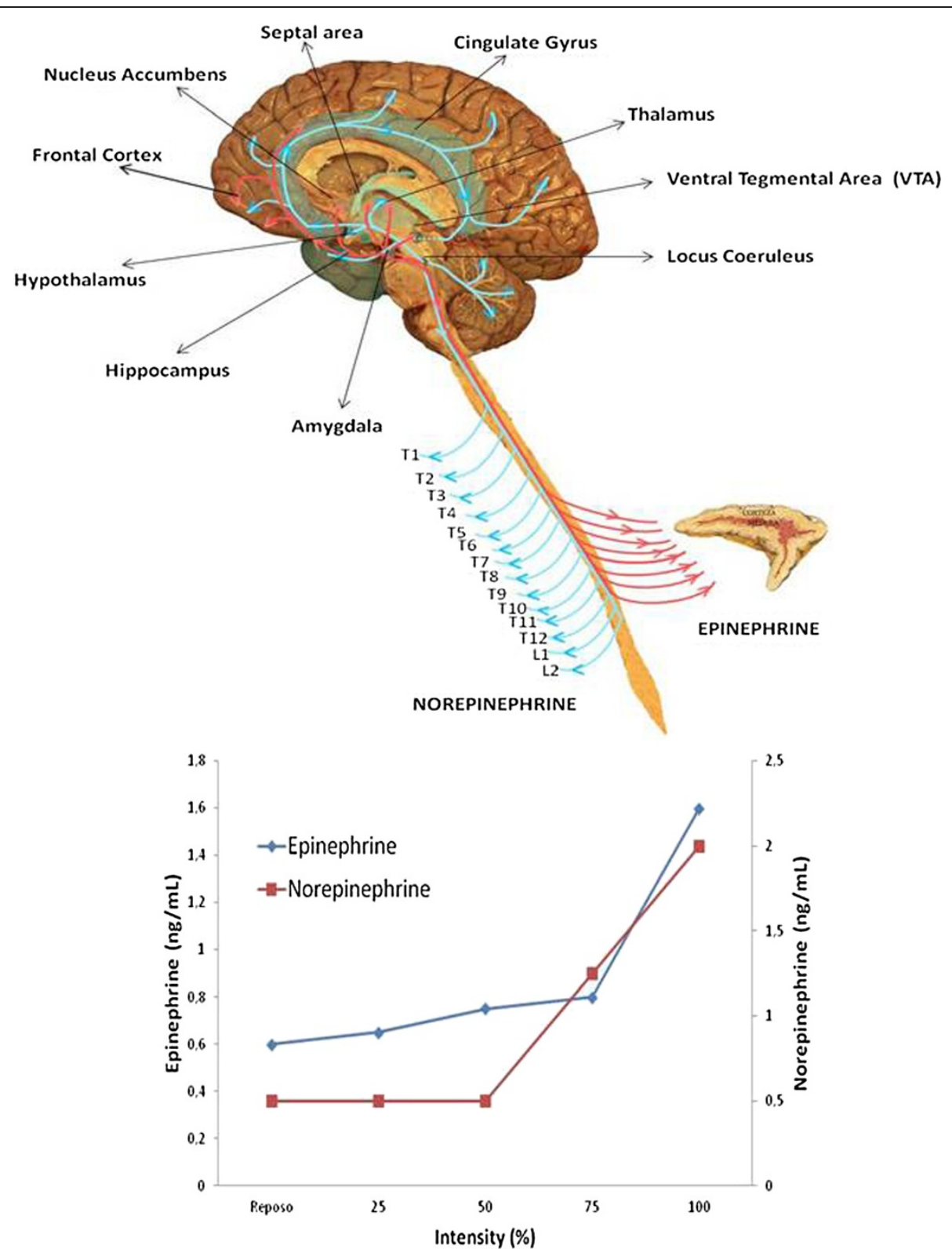

Figure 4 Catecholamine release during an incremental exercise test. Data unpublished.

Physiological significance of the integrated physiological response to having reached the anaerobic threshold

The directing action of the CC allows for the coordination of the autonomous and motor systems, suggesting that the AT can be identified in the many - and apparently unrelated - ways described. The change in response to the AT having been reached probably allows the CNS to interpret that the organism is reaching its limits. At the same time, the different signals sent by the CNS may therefore also serve as a feedback system, as suggested by several authors [34]. Thus, increases in lactate, catecholamines and ventilation, etc. provide the higher centres related with consciousness with information that the organism is close to the $\mathrm{VO}_{2}$ max.

Of all the variables that are measurable during intense exercise, the HR has been the most studied over the last 20 years [35-37]. Although still a matter of debate, it is thought that the HR obeys a chaotic behavioural model [38]. Such behaviour may be accentuated once the AT has been reached $[39,40]$. The physiological response of an organism beyond the AT may also be chaotic. Such non-linear, chaotic behaviour explains why the response 


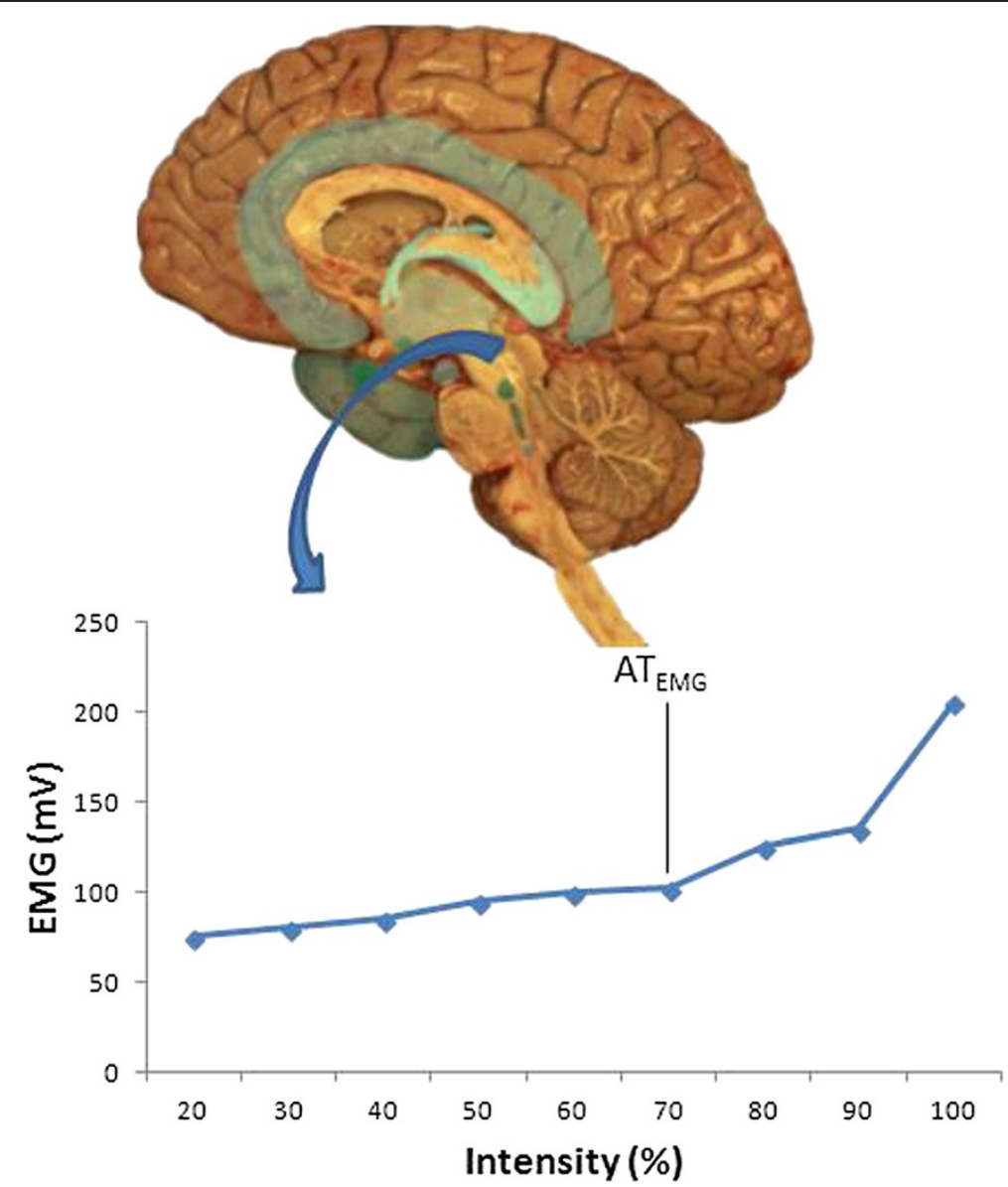

Figure 5 Muscular electrical activity changes during an incremental exercise test. Data unpublished. EMG: electromyography.

is limited to trying to maintain the balance between energy availability and use.

\section{Conclusion}

In summary, the changes in the composition of the saliva, electromyographic activity, plasma catecholamines, and the other variables mentioned in this work, act as parts of a complex system that allows the CC to coordinate an effective response. An increase in load after reaching the AT means the organism must start to face homeostatic difficulties; the CC therefore sends information to all kinds of other control centres, many of which may not be directly linked to exercise. Thus, beyond the AT, the disorder increases for some variables (e.g., ventilation) or leads to a change in the slope away from linear (e.g., as seen for the HR). This change in response could be indicative that the organism would face failure if the load continued to increase. To avoid this, the CC manages the efferent signals that show the organism that it is running out of homeostatic potential. Unfortunately, we are a long way from knowing how the $\mathrm{CC}$ detects variations in these variables and coordinates its response.

\section{Competing interests}

The authors declare that they have no competing interests.

\section{Authors' contributions}

$A B P, J J R$ and FJC conception and design of this review; ABP and FJC drafted manuscript; JJR prepared figures; ABP, JJR and NM edited and revised manuscript; All authors read and approved the final manuscript.

\section{Acknowledgments}

The authors would like to thank Javier Butragueño for technical assistance.

\section{Author details}

${ }^{1}$ Department of Health and Human Performance, Technical University of Madrid, Martín Fierro 7, 28040 Madrid, Spain. ${ }^{2}$ Department of Musculoskeletal Surgery, University of Salerno School of Medicine and Surgery, Salerno, Italy. ${ }^{3}$ Centre for Sports and Exercise Medicine, Queen Mary University of London, London, England.

Received: 29 November 2013 Accepted: 14 April 2014 Published: 24 April 2014

\section{References}

1. Gondim FJ, Zoppi CC, Pereira-da-Silva L, De Macedo DV: Determination of the anaerobic threshold and maximal lactate steady state speed in equines using the lactate minimum speed protocol. Comp Biochem Physiol A Mol Integr Physiol 2007, 146:375-380.

2. Hopkins SR, Stary CM, Falor E, Wagner H, Wagner PD, McKirnan MD: Pulmonary gas exchange during exercise in pigs. J Appl Physiol 1999, 86:93-100. 
3. McDonough P, Kindig CA, Erickson HH, Poole DC: Mechanistic basis for the gas exchange threshold in Thoroughbred horses. J Appl Physiol 2002, 92:1499-1505

4. Pilis W, Zarzeczny R, Langfort J, Kaciuba-Uścilko H, Nazar K, Wojtyna J: Anaerobic threshold in rats. Comp Biochem Physiol Comp Physiol 1993, 106:285-289.

5. Brooks GA: Anaerobic threshold: review of the concept and directions for future research. Med Sci Sports Exerc 1985, 17:22-34.

6. Jones NL, Ehrsam RE: The anaerobic threshold. Exerc Sport Sci Rev 1982, 10:49-83.

7. Francis $K$ : The use of the ventilatory anaerobic threshold for the development of exercise guidelines. Comput Biol Med 1989, 19:307-317.

8. Meyer T, Lucia A, Earnest CP, Kindermann W: A conceptual framework for performance diagnosis and training prescription from submaximal gas exchange parameters-theory and application. Int J Sports Med 2005, 26(Suppl 1):S38-48.

9. Hansen D, Stevens A, Eijnde BO, Dendale P: Endurance exercise intensity determination in the rehabilitation of coronary artery disease patients: a critical re-appraisal of current evidence. Sports Med 2012, 42:11-30.

10. Billat LV: Use of blood lactate measurements for prediction of exercise performance and for control of training. Recommendations for longdistance running. Sports Med 1996, 22:157-175.

11. Bosquet $L$, Leger $L$, Legros $P$ : Methods to determine aerobic endurance. Sports Med 2002, 32:675-700.

12. Wasserman K, Mcllroy MB: Detecting the Threshold of Anaerobic Metabolism in Cardiac Patients during Exercise. Am J Cardiol 1964, 14:844-852.

13. Wasserman K, Whipp BJ, Koyl SN, Beaver WL: Anaerobic threshold and respiratory gas exchange during exercise. J Appl Physiol 1973, 35:236-243.

14. Skinner JS, McLellan TH: The transition from aerobic to anaerobic metabolism. Res Q Exerc Sport 1980, 51:234-248.

15. Orr GW, Green HJ, Hughson RL, Bennett GW: A computer linear regression model to determine ventilatory anaerobic threshold. J Appl Physiol Respir Environ Exerc Physiol 1982, 52:1349-1352.

16. Mader A, Heck H: A theory of the metabolic origin of "anaerobic threshold". Int J Sports Med 1986, 7(Suppl 1):45-65.

17. Kindermann W, Simon G, Keul J: The significance of the aerobic-anaerobic transition for the determination of work load intensities during endurance training. Eur J Appl Physiol Occup Physiol 1979, 42:25-34.

18. Stegmann H, Kindermann W, Schnabel A: Lactate kinetics and individual anaerobic threshold. Int J Sports Med 1981, 2:160-165.

19. Sjodin B, Jacobs I: Onset of blood lactate accumulation and marathon running performance. Int J Sports Med 1981, 2:23-26.

20. Faude O, Kindermann W, Meyer T: Lactate threshold concepts: how valid are they? Sports Med 2009, 39:469-490.

21. Bishop DJ: Comments on Point:Counterpoint: Muscle lactate and $\mathrm{H}(+)$ production do/do not have a 1:1 association in skeletal muscle. Confusion concerning the lactate proton ratio: a problem of definition? J Appl Physiol 2011, 110:1494-1495.

22. Dempsey JA, Vidruk EH, Mitchell GS: Pulmonary control systems in exercise: update. Fed Proc 1985, 44:2260-2270.

23. Davies CT, Few J, Foster KG, Sargeant AJ: Plasma catecholamine concentration during dynamic exercise involving different muscle groups. Eur J Appl Physiol Occup Physiol 1974, 32:195-206.

24. Jurimae J, von Duvillard SP, Maestu J, Cicchella A, Purge P, Ruosi S, Jurimae T, Hamra J: Aerobic-anaerobic transition intensity measured via EMG signals in athletes with different physical activity patterns. Eur J Appl Physiol 2007, 101:341-346.

25. Chicharro JL, Perez M, Carvajal A, Bandres F, Lucia A: The salivary amylase, lactate and electromyographic response to exercise. Jpn J Physiol 1999, 49:551-554

26. Conconi F, Ferrari M, Ziglio PG, Droghetti $P$, Codeca L: Determination of the anaerobic threshold by a noninvasive field in man. Boll Soc Ital Biol Sper 1980, 56:2504-2510

27. Crisafulli A, Tocco F, Pittau G, Caria M, Lorrai L, Melis F, Concu A: Detection of lactate threshold by including haemodynamic and oxygen extraction data. Physiol Meas 2006, 27:85-97.

28. Williams PL: Anatomía de Gray. 38th edition. Madrid (España): Harcour Brace; 1998.

29. Burke RE: Motor units: anatomy, physiology and functional organization. In Handbook of physiology, Section 1: the nervous system. Volume Il: motor control. Edited by Brooks VB. Bethesda, Maryland: American physiological society; 1981.

30. Gossard J-P, Dubuc R, Kolta A: The interactions between locomotion and respiration. Breathe, Walk, and Chew: The Neural, Challenge 2010, 187:173.

31. Williamson JW: The relevance of central command for the neural cardiovascular control of exercise. Exp Physiol 2010, 95:1043-1048.

32. Greenwood BN, Fleshner M: Exercise, stress resistance, and central serotonergic systems. Exerc Sport Sci Rev 2011, 39:140-149.

33. Rossignol S: Neural control of stereotypic limb movements. In Handbook of physiology, Section 12 Exercise: regulation and integration of multiple systems. Edited by Brooks VB. Bethesda, Maryland: American physiological society; 1996.

34. Herman JP, McKlveen JM, Solomon MB, Carvalho-Netto E, Myers B: Neural regulation of the stress response: glucocorticoid feedback mechanisms. Braz J Med Biol Res 2012, 45:292-298.

35. Borresen J, Lambert MI: Autonomic control of heart rate during and after exercise : measurements and implications for monitoring training status. Sports Med 2008, 38:633-646.

36. Sandercock GR, Brodie DA: The use of heart rate variability measures to assess autonomic control during exercise. Scand J Med Sci Sports 2006, 16:302-313.

37. Freeman JV, Dewey FE, Hadley DM, Myers J, Froelicher VF: Autonomic nervous system interaction with the cardiovascular system during exercise. Prog Cardiovasc Dis 2006, 48:342-362

38. Lombardi F: Chaos theory, heart rate variability, and arrhythmic mortality. Circulation 2000, 101:8-10.

39. Cottin F, Medigue C, Lopes P, Lepretre PM, Heubert R, Billat V: Ventilatory thresholds assessment from heart rate variability during an incremental exhaustive running test. Int J Sports Med 2007, 28:287-294.

40. Sarmiento S, García-Manso JM, Martín-González JM, Vaamonde D, Calderón J, Da Silva-Grigoletto ME: Heart rate variability during high-intensity exercise. J of Syst Sci and Complexity 2013, 26:104-116.

doi:10.1186/2052-1847-6-17

Cite this article as: Peinado et al:: Responses to increasing exercise upon reaching the anaerobic threshold, and their control by the central nervous system. BMC Sports Science, Medicine, and Rehabilitation 2014 6:17.

\section{Submit your next manuscript to BioMed Central and take full advantage of:}

- Convenient online submission

- Thorough peer review

- No space constraints or color figure charges

- Immediate publication on acceptance

- Inclusion in PubMed, CAS, Scopus and Google Scholar

- Research which is freely available for redistribution 